\title{
On the inferred independence of paired watchkeepers'
}

\author{
Ben B. Morgan and Earl A. Alluisi ${ }^{2}$ \\ UNIVERSITY OF LOUISVILLE
}

\begin{abstract}
Abstraet
Twenty-four Ss performed a visual watchkeeping task over a 30-min. period. Eight of the Ss worked singly, and 16 worked as pairs of watchkeepers. The proportion of signals detected in the paired-S condition (.906) was significantly greater than in the single-S condition (.735), but the estimated likelihood of an individual watchkeeper's detecting a signal was essentially identical in the two conditions (.693 and .735, for the 2- and 1-man systems, respectively). The results are interpreted as supporting the inference that the watchkeeping behaviors of paired Ss are operationally "independent."

\section{Problem}

Two observers in a watchkeeping task should jointly miss fewer signals than a single observer working alone. This conclusion follows logically from an application of the rules for combining simple probabilities with the assumption that the performances of the observers are independent.

That is to say, if $\mathbf{P}$ is the probability of a single observer's detecting a signal, and $(1-P)$ is the probability of his missing the signal, then the probability of both of two similar independent observers' missing the signal is $(1-\mathrm{P})^{2}$. The probability of either or both of them detecting the signal is the complement of this, or $1-(1-P)^{2}$. Watchkeeping behavior will deviate from the predictions of this simple scheme to the extent that men fail to perform identical watchkeeping tasks in a statistically independent manner.

The present experiment was designed to permit some inference about the operational independence of two watchkeepers jointly monitoring a single display.

\section{Subjects}

Twenty-four male undergraduates at the Georgia Institute of Technology served as Ss. All were volunteers from an introductory psychology class, and all evidenced normal or corrected $20 / 20$ visual acuity. They were assigned at random to one of two experimental groups: a group of $8 \mathrm{Ss}$ who worked singly, or a group of 16 Ss who worked as pairs of watchkeepers.

\section{Apparatus}

An oscilloscope was used to provide the visual display for the watchkeeping task. A small spot of light ("blip") swept horizontally across the 6-in screen about once every $3 \mathrm{sec}$. The critical signal was a momentary displacement of the "blip" to a position approximately 1.5 in above the central axis of the screen.

This signal was generated and scheduled with an audio tape recorder, the output of which was connected to the $y$-axis input of the oscilloscope. The occurrence of an audio-frequency signal on the tape (prerecorded with a 256-cps tuning fork) provided the electronic signal for the 'blip"' displacement. The Mackworth (1950, p. 13) schedule of intersignal intervals was used; thus, there were 12 signals per half-hour period of watchkeeping.

Responses were made by S's pressing a telegraph key that was attached to the arm of the classroom-desk-type chair in which he was seated. The key was mounted on a styrofoam base so that its operation was essentially silent. When a pair of Ss worked, both were seated in desks facing the display, but they were separated from each other by an opaque screen that extended from the back of the booth to a line 24 in from the center front of the display screen. Both desks were equipped with response keys, and both Ss were instructed to respond when they detected a critical signal. All signals and responses were recorded on an event-recording kymograph.

\section{Procedure}

The experiment was conducted in a small $\left(371 \mathrm{ft}^{3}\right)$, closed experiment booth that was nearly cubic in shape. The interior of the booth was dimly illuminated by the light from the screen of the oscilloscope. Careful control of temperature and air flow was maintained at levels that had been rated "most comfortable" in an earlier study. The oscilloscope was placed on a table at one end of the booth with its screen 36 in in front of, and at the average eye level of, the seated $S$.

Prior to each 30-min. experimental watchkeeping session, S was relieved of his watch (if any) and was instructed concerning the purposes of the study and the nature of the watchkeeping task. Those in the paired-S condition were told that they could converse freely about any matter except the watchkeeping task. Then, the critical signal to be detected was demonstrated, and $\mathrm{S}$ was required to respond correctly to two successive demonstrations, thereby providing $\mathrm{E}$ with evidence that the instructions had been understood.

\section{Results}

The data available on the response record permitted the scoring of two aspects of performance: false responses and detected signals (or its complement, missed signals). A signal was scored as having been detected when a response was made within a 5-sec. period after the signal presentation. Both measures were scored for the watchkeeping system, rather than for individuals. Therefore, if either (or both) $S(s)$ in the paired-S condition responded within a 5-sec. interval, the system was scored with one detection (or, with o ne false response, depending on whether a signal had been presented). 
False responses. The mean number of false responses made during the $30-\mathrm{min}$. watch was 1.375 for the $8 \mathrm{Ss}$ in the single-S condition; it was identical for the 8 pairs of Ss in the paired-S group. The difference, being nil, is not statistically significant.

$\mathrm{M}$ is sed signals. The mean number of missed signals was 3.175 (about 27\%) with the single-S condition, and 1.125 (about 9\%) with the paired-S condition. The difference is statistically significnat (Mann-Whitney $\mathrm{U}$-test, $\mathrm{U}=10.5 ; \mathrm{p}<.02)$. Thus, the likelihood that $\mathrm{S}$ would miss a signal in the single-s condition is, $\left(1-P_{1}\right)=.265$; and, the likelihood of his detecting a signal is, $P_{1}=1-.265=.735$. The likelihood that two Ss would jointly miss a signal in the paired-S condition is, $\left(1-\mathrm{P}_{2}\right)^{2}=.094$; the likelihood of one S's detecting the signal in this condition can be estimated as, $P_{2}=1$ $(.094)^{1 / 2}=.693$. The difference between $P_{1}$ and $P_{2}$ is not statistically significant $(z=0.186 ; p>.85)$.

\section{Discussion}

About $17 \%$ more signals were detected in the paired-S condition of this study than in the single-S condition. These results compare favorably with those of Shafer's study (1949) of performances in monitoring an audiovisual sonar display. He found that the combined performance of two watchkeepers working together produced from $11 \%$ to $20 \%$ more detections than either individual working alone, and that the combined performance of three watchkeepers produced $6 \%$ to $15 \%$ more detections than two.

On the other hand, there is no evidence to indicate that there is any facilitation of (nor decremental effect on) the individual performances of the two observers who are keeping watch together. Rather, the estimates of individual detection likelihoods are quite close $\mathrm{P}_{1}=$ .735 , and $\mathrm{P}_{2}=.693$ ). This finding is essentially similar to that of Bergum \& Lehr (1962) whose Ss monitored a circular light display for $90 \mathrm{~min}$.
The parsimonious interpretation of the present results seems to be that the detection behavior of two watchkeepers can be treated as statistically independent. To the extent that this interpretation can be held valid, alternate interpretations must be held invalid. Thus, if an "activation" theorist (cf. Deese, 1955; Frankman \& Adams, 1962) were to argue that multiple monitoring systems result in better overall performance because the individual monitors are allowed to interact (thereby increasing their background sensory input and individual levels of activation), we would have to conclude that our data fail to support their argument! If such facilitation does occur in certain individual cases, there must be a compensating number of cases in which decrements occur, for the general effect is neither-and the parsimonious interpretation remains the one previously stated.

\section{References}

BERGUM, B. O., \& LEHR, O. J. Vigilance performance as a function of paired monitoring. J. appl. Psychol., 1962, 46, 341-343. DEESE, J. Some problems in the theory of vigilance. Psychol. Rev., 1955, 62, 359-367.

FRANKMAN, J. B., \& ADAMS, J. A. Theories of vigilance. Psychol. Bull., 1962, 59, 257-272.

MACKWORTH, N. H. Researches on the measurement of human performance. Med. Res. Council Special Rep. Series 268, H. M. Stationery Off., London, England, 1950.

SHAFER, T. H. Detection of a signal by several observers. USN NEL Res. Rep., 1949, No. 101.

\section{Notes}

1. The data reported in this study were collected at the Georgia Institute of Technology as one of several experiments conducted by a class in applied experimental psychology. The junior author instructed the class and supervised the research. The authors acknowledge their debt to the other participants in the class (Messrs Carter, Childs, Hawkins, Johnson, Landgrebe, and Stoddard) and to Dr. E. H. Loveland (Director of the School of Psychology) for their help and encouragement in the performance of this research.

2. Address of Professor Earl A. Alluisi is Department of Psychology and Social Anthropology, University of Louisville, Louisville, Ky. 40208 . 